\title{
Twin reversed arterial perfusion syndrome: a rare but critical event of twin pregnancy
}

\author{
Urvashi Barman Singh $^{1 *}$, Akanksha Mishra ${ }^{1}$, Kahkashan Bano $^{2}$
}

\begin{abstract}
${ }^{1}$ Department of Obstetrics \& Gynaecology, M.L.N Medical College, Allahabad, Uttar Pradesh, India
${ }^{2}$ Department of Obstetrics \& Gynaecology, District Hospital, Siddharthnagar, Uttar Pradesh, India
\end{abstract}

Received: 28 December 2014

Accepted: 11 January 2015

\author{
*Correspondence: \\ Dr. Urvashi Barman Singh, \\ E-mail: urvashibarmansingh@gmail.com
}

Copyright: (C) the author(s), publisher and licensee Medip Academy. This is an open-access article distributed under the terms of the Creative Commons Attribution Non-Commercial License, which permits unrestricted non-commercial use, distribution, and reproduction in any medium, provided the original work is properly cited.

\begin{abstract}
Twin-Reversed Arterial Perfusion (TRAP) sequence is also known as acardiac twin gestation or chorioangiopagus parasiticus, it is a rare and unique complication of monozygotic monochorionic twin pregnancies. 35 year old 8 gravida four alive issues and one spontaneous abortion. Patient came with complaint of pain in abdomen since 8 hours. She was having an ultrasonography report of twin pregnancy of 28 weeks gestation with one fetus alive and normal while other fetus was anomalous fetus FHS of first fetus was localised while FHS of other fetus was not localised. Twin-Reversed Arterial Perfusion (TRAP) sequence is a rare complication of monochorionic multiple gestation. Accurate antenatal diagnosis is essential to improve the prognosis of this rare entity.
\end{abstract}

Keywords: Monochorionic twin, Twin-reversed arterial perfusion (TRAP), Acardiac twin, Amorphous twin

\section{INTRODUCTION}

Multiple pregnancy accounts for $1.5 \%$ of all pregnancies, complicated by congenital malformations twice as often as singletons. TRAP sequence is also known as acardiac twin gestation or chorioangiopagus parasiticus, it is a rare and unique complication of monozygotic monochorionic twin pregnancies. This condition occurs in 1 in 35000 pregnancies and in $0.3 \%$ of all monozygotic twin gestations. ${ }^{1,2}$ The risk of recurrence was estimated $1: 10000$. $^{3,4}$ TRAP sequence is characterised by a structurally normal pump twin perfusing an anomalous recipient twin via an artery to artery anastomosis in a reverse direction. The anomalous fetus is either acardiac or has severely anomalous cardiac structure.

\section{CASE REPORT}

We here by present a case of 35 year old G8 P6+1, four alive issues and one spontaneous abortion. Patient came with complaint of pain in abdomen since 8 hours. She was having an ultrasonography report of twin pregnancy of 28 weeks gestation with one fetus alive and normal while other fetus was anomalous fetus. On examination her vitals were stable, uterine contractions were present, FHS of first fetus was localised while FHS of other fetus was not localised. Her cervix was $3 \mathrm{~cm}$ dilated and 50\% effaced, bag of membranes was present. Patient delivered first baby which was normal and expired immediately after birth due to either prematurity, congestive cardiac failure. The other baby was anomalous. The intact placenta was monochorionic diamniotic and weight 300 grams. On careful examination of anomalous baby it was amorphous baby with abnormal cephalic pole and acephaly with abnormally placed upper limbs, both upper and lower limbs were maldeveloped. Insertion of umbilical cord was seen below the upper limb buds. Amorphic twin was evaluated by infantogram, CT and MRI scans. Careful autopsy was negative for any of the intra-abdominal or thoracic organs and absence of cardiac structures. Chromosomal analysis of amorphous twin was normal. 


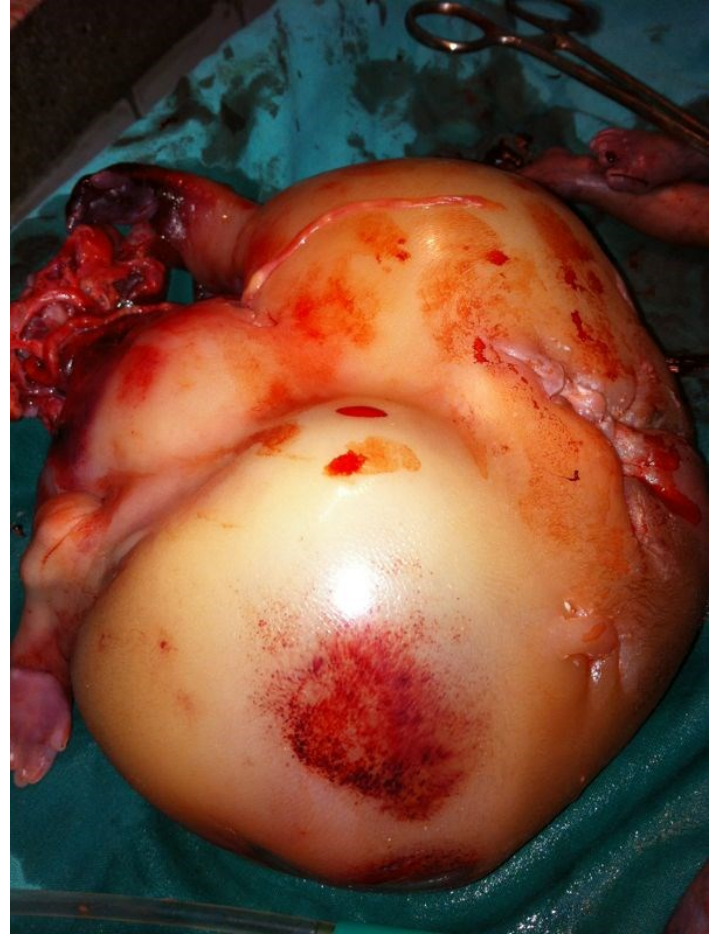

Figure 1: The amorphus twin.

\section{DISCUSSION}

TRAP sequence is a rare complication of monochorionic multiple pregnancy. It is classified according to the degree of cephalic a truncal maldevelopment. The first type is acardiac-acephalus, where no cephalic structures present. The second is acardius-ancephalus where some cranial structure and or neural tissue is present. The third is acardius-acormus with cephalic structure but no truncal structures present. The fourth type is acardius-amorphous with no distinguishable cephalic or truncal structure. ${ }^{5}$

The pathogenesis of TRAP is controversial, with two main pathogenetic hypothesis proposed ${ }^{2}$

1. Deep placental anastomoses in early embryogenesis cause malformation of the acardiac twin. The early pressure flow in one twin exceeds that of the other and leads to reversed circulation in the twin who exhibits perfusion.

2. A primary defect in embryogenesis in one twin leads to failure of cardiac development. The normal twin then perfuses the acardiac twin via artery-artery anastomoses. However, the anastomoses are not responsible for the cardiac anomaly.

This abnormal circulation may result in early tissue hypoxia with resultant disruption of development of the cardiovascular system and a cascade of disruption of organ development in the recipient twin. Because the blood first perfuse the lower segment of the anomalous twin, the lower limbs and genitalia receive comparatively more oxygen than the upper segment of the body. ${ }^{6,7}$
The mortality of the cardiac twin is $100 \%$, and the perinatal mortality of the pump twin is reported to be around $50 \%$. The poor outcome of the pump twin is primarily due to congestive heart failure, cord entanglement or prematurity. ${ }^{8}$ The mortality rate of the pump twin appears to correlate with the size of the acardiac twin. A larger, more developed acardiac twin (with multiple internal organs such as kidney) is associated with a significant increase in the perinatal mortality of the pump twin. ${ }^{9}$

Other poor prognostic indicators are polyhydramnios and preterm delivery (before 32 weeks' gestation). The prominent features of the recipient twin are: total or partial absence of cranial vault, holoprosencephaly, absent facial structures, anophthalmia, microphthalmia, cleft lip, cleft palate, absent or rudimentary limbs, diaphragmatic defects, absent lungs and heart, esophageal atresia, ventral wall defects, ascites, absent liver and gall bladder, edema of the skin and single umbilical artery.

The twin reversed-arterial perfusion sequence carries a poor prognosis with a mortality rate of approximately $50 \%$. The prognosis is directly related to the weight of the recipient twin and the pump twin. Higher the weight of the recipient twin the more likely is the development of cardiac insufficiency in the pump twin. The weight of the cardiac twin cannot be calculated from the values of the circumference, abdominal circumference and femur length using the standard formulae. Instead, the weight (in grams) of the acardiac twin is calculated using the formula: $(1.2 \times$ longest length 2$)-(1.7 \times$ longest length $)$.

Tan and Sepulveda recommended that intra-fetal ablation is the treatment of choice for TRAP sequence because it is simpler and more effective in prolonging pregnancy than cord occlusion. ${ }^{10}$ On the other hand, Hecher et al. found that fetoscopic laser coagulation of placental anastomosis or the umbilical cord of the acardiac twin was successful in $82 \%$ by laser alone and in a further $15 \%$ by laser coagulation in combination with bipolar forceps. The success rate is better in the early second trimester and less successful in the third trimester because the umbilical cord is more edematous with higher content of Wharton's jelly. ${ }^{11}$

\section{CONCLUSION}

Twin-Reversed Arterial Perfusion (TRAP) sequence is a rare complication of monochorionic multiple gestation. Accurate antenatal diagnosis is essential to improve the prognosis of this rare entity. Though many patients can benefit from conservative treatment, minimally invasive treatment modalities for the vascular anastomosis improve the outcome of the pump twin.

\section{Funding: No funding sources \\ Conflict of interest: None declared \\ Ethical approval: Not required}




\section{REFERENCES}

1. James WH. A note on the epidemiology of acardiac monsters. Teratology. 1977;16:211-6.

2. Sogaard K, Skisted L, Brocks V. Acardiac twins: pathphysiology diagnosis, outcome and treatment. Six cases and review of the literature. Fetal Diagn Therapy. 1999; 14:53-9.

3. Napolitani FD, Schreiber I. The acardiac monster: a review of the world literature and presentation of 2 cases. Am J Obstet Gynaecol. 1960;80:582-9.

4. Leite JMB, Couto JCF. Twin, acardiac at 24 weeks, 2009. Available at: http://www.thefetus.net. Accessed 1 January 2010

5. Mohanty C, Mishra OP, Singh CP, Das BK, Singla PN. Acardiac anomaly spectrum. Teratology. 2000;62:356-9.

6. Luiz N. Trap syndrome. Indian Paediatr. 2003;40:683-4.

7. Weisz B, Peitz R, Chayen B, Oren M, Zalel Y, Achiron $\mathrm{R}$, et al. Tailored management of twin reversed arterial perfusion (TRAP) sequence. Ultrasound Obstet Gynaecol. 2004;23:451-5.

8. Moore T, Gale S, Benirschke K. Perinatal outcome of forty-nine pregnancies complicated by acardiac twinning. Am J Obstet Gynaecol. 1990;163:907-12.

9. Peak B, Goldberg J, Albanese C. Prenatal diagnosis. World J Surg. 2003;27:27-37.

10. Tan TYT, Sepulveda W. Acardiac twin: a systematic review of minimally invasive treatment modalities Ultrasound Obstet Gynecol. 2003;22:409-19.

11. Hecher K, Hackelor BJ, Ville Y. Umbilical cord coagulation by microendoscopy at 16 weeks gestation in an acardiac twin. Ultrasound Obstet Gynaecol. 1997;10:130-2.

DOI: $10.5455 / 2320-1770 . i j \operatorname{cog} 20150260$

Cite this article as: Singh UB, Mishra A, Bano K. Twin reversed arterial perfusion syndrome: a rare but critical event of twin pregnancy. Int J Reprod Contracept Obstet Gynecol 2015;4:289-91. 